\title{
Hemicellulose-Based Polymers Processing and Application
}

\author{
Lisong Hu, Xuezhi Fang, Menghao Du, Fan Luo, Shaohai Guo \\ Research Institute of Subtropical Forestry, Chinese Academy of Forestry, Fuyang, China \\ Email: lisohu@hotmail.com
}

How to cite this paper: Hu, L.S., Fang, X.Z., Du, M.H., Luo, F. and Guo, S.H. (2020) Hemicellulose-Based Polymers Processing and Application. American Journal of Plant Sciences, 11, 2066-2079.

https://doi.org/10.4236/ajps.2020.1112146

Received: September 10, 2020

Accepted: November 25, 2020

Published: December 23, 2020

Copyright $\odot 2020$ by author(s) and Scientific Research Publishing Inc. This work is licensed under the Creative Commons Attribution International License (CC BY 4.0).

http://creativecommons.org/licenses/by/4.0/

\begin{abstract}
Hemicellulose is the second most abundant biomass in the world. Because of its unique chemical structure, hemicellulose has attracted more and more research and industry application under the background of fossil resource shortage and drawbacks. Hemicellulose is tended to be modified with esterification, etherification, cross-linkage and so on. These reactions change hemicellulose properties, so that it could be applied in many fields such as medical field, films, hydrogels, conductive polymers. Herein, we reviewed structure, isolation, reaction and applications of hemicellulose. Especially the useful pathways to change the hydrophilic character of hemicelluloses to hydrophobic are reviewed and several applications of these materials are discussed.
\end{abstract}

\section{Keywords}

Hemicellulose, Extraction, Materials, Hydrogel, Polymers

\section{Introduction}

Since fossil resources are nonrenewable and lead to environmental issues [1], much research and considerable work have been done to alternate energy resources such as biomass, wind, geothermal and solar energy in order to meet the developmental and environmental requirements [2] [3] [4]. Among these resources, utilization of biomass has attracted a lot of attention over the past several decades. Biomass is considered to be the only sustainable and carbon-neutral source for liquid fuels, which has potential to replace or partly replace fossil resources.

Biomass is organic materials that are plant or animal based, such as crops, trees, fiber residues, aquatic plants, forestry and wood residues, agricultural wastes, and other non-fossil organic materials. Chemically, biomass is a form of lignocellulose and essentially composite plant structural material. Biomass is composite in nature, being composed in varying proportions of three readily 
identifiable polymeric constituents: cellulose; hemicellulose; and lignin. Generally, in most plants, the ratios of cellulose, hemicellulose and lignin verify depending on the kind of wood. For example in softwoods, hemicellulose is $20 \%$ $30 \%$ of dry plant biomass, however, in hardwood, as high as $40 \%$ (see Table 1).

\subsection{Lignin}

Lignin is complex polymers with large molecular weight, which has the structure of phenylpropane units and coupling with the generic term for a large group of aromatic polymers resulting from the oxidative combinatorial coupling 4-hydroxyphenylpropanoids. The main precursors of lignin are trans-coniferyl alcohol (1) trans-sinapyl alcohol (2) and trans-p-coumaryl alcohol (3). These precursors biosynthesize lignin and their chemical structure of precursors is illustrated in Figure 1. The phenylpropane units are through C-O-C and $\mathrm{C}-\mathrm{C}$ linkages with random order. In the cell walls, lignin is like a binder to combine hemicellulose and cellulose and makes cells more rigid and impervious.

\subsection{Cellulose}

Cellulose, the main polysaccharide of wood, is the most abundant resource on the earth. Cellulose exists widely in plants, animals and some bacteria. Cellulose, a linear polymer, is established as the repeat unit of anhydro-D-glucopyranose for cellulose chains (Figure 2) connected by $\beta$-1,4-glycosidic bonds. Because of its<smiles>[2H]c1cc(/C=C/CO)cc([2H])c1O</smiles>

Figure 1. Structure of lignin precursors phenylpropanoid units [6].

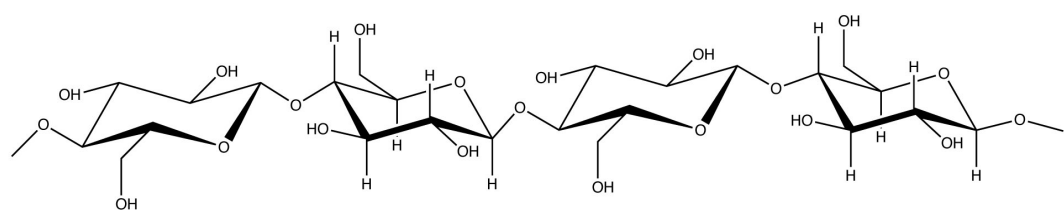

Figure 2. Structure of cellulose.

Table 1. Compositions of biomass [5].

\begin{tabular}{ccc}
\hline Constituents & \multicolumn{2}{c}{ Weight (\%) } \\
\cline { 2 - 3 } & Softwoods & Hardwoods \\
\hline Cellulose & $40-50$ & $40-50$ \\
Hemicellulose & $20-30$ & $25-40$ \\
Lignin & $25-35$ & $20-25$ \\
Extractives & $0-25$ & $0-25$ \\
\hline
\end{tabular}


linear structure and intramolecular hydrogen bonding, this polymer forms a very organized structure in the wood fibers. Cellulose fibrils contain alternating crystalline and amorphous regions. The fibrils are highly ordered in the crystalline region, whereas they are less ordered in the amorphous regions. This is an important property since cellulose is much more susceptible to react in its amorphous regions rather than the crystalline regions due to the accessibility of the reagents. Molecular weight measurements have shown that the degree of polymerization (DP) of cellulose is in the range of 10,000 to 15,000 depending on the source. The hydroxy groups formed glycosidic bond and some hydroxy groups on one chain interaction with another chain by Van Der Waals force. These chains are hydrophobic, so that, cellulose is insoluble in wanter and some high polarized solvents. Nowadays, cellulose is applied to nanocontainers, hydrogels, flame retardant etc.

\section{Hemicellulose}

\subsection{General}

Hemicellulose is the second most abundant biomass in the world, which is about $20 \%-30 \%$ weight of lignocellulosic materials (LCMs). Over past decades, Much research have been done to conversion of biomass especially lignocellulosic materials to replace the fossil based product, e.g. biomass fuels, biomass ethanol and organic materials. Hemicelluloses widely existed in nature are a class of hetero-polysaccharides present in the primary and secondary cell wall of wood and annual plants together with cellulose and lignin. Many agricultural crops or their residues, such as sorghum, sugarcane, corn stalks and cobs, cereal straws and husks, as well as forest and pulping side-streams from hardwoods, are good sources for xylans. For example, the xylan content in oat spelts is over $30 \%$ with an estimated production of 60 billion tons per year. Unlike cellulose, hemicelluloses consist of different monosaccharide units such as glucose, xylose, mannose, galactose, arabinose, fucose, glucuronic acid, and galacturonic acid in various amounts or traces dependent on the natural source. The units of hemicellulose are illustrated in Figure 3.

HEXOSES

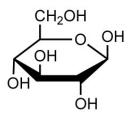

$\beta$-D-Glc $p$
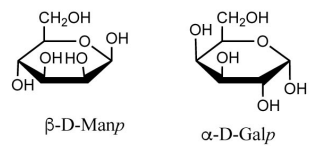

HEXURONIC ACIDS

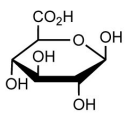

$\beta$-D-GlcpU

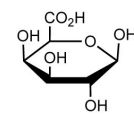

$\beta$-D-GalpU

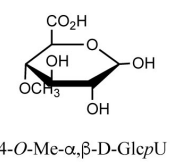

PENTOSES
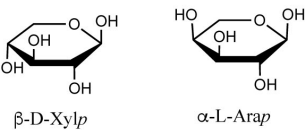

$\alpha$-L-Arap

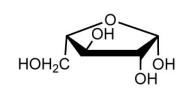

$\beta$-L-Araf

DEOXYHEXOSES

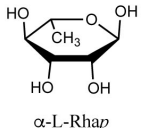

$\alpha-$-Lhap
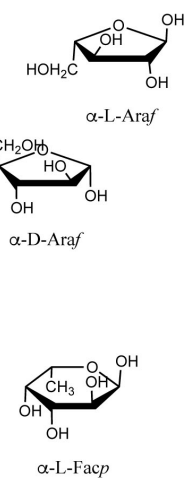

Figure 3. Units of hemicellulose. 
The typical chemical structure of hemicellulose is shown in Figure 4. Sugar units of hemicellulose linkage in different ways mainly form xylans, mannans, glucomannans, and xyloglucans [7]. In addition, the polymer chains of hemicelluloses have short branches and are amorphous. Because of the amorphous morphology, hemicelluloses are partially soluble or soluble in water. The backbone of the chains of hemicelluloses can be a homopolymer (generally consisting of single sugar repeat unit) or a heteropolymer (mixture of different sugars). The hemicelluloses in softwoods differ in structure from those in hardwoods. Different hemicellulose compositions, structures and amounts could be obtained from different sources of different biomass. For example, the main hemicellulose in hardwood is O-acetyl-(4-O-methylglucurono) xylan [8] [9] [10]. In backbone of the hardwood, approximately $10 \%$ of xylopyranose are substituted by 4 -o-methyl glucuronic acid. In contrast, the predominant component of softwood hemicellulose is O-acetyl-galactoglucomannan (see Figure 5). The backbones of softwood hemicellulose are composed of mannose units combining with glucose units randomly [11] [12] [13]. Galactoglucomannans are the principal hemicelluloses in softwood, whereas glucuronoxylan is the main hemicellulose in hardwood species (Figure 6).

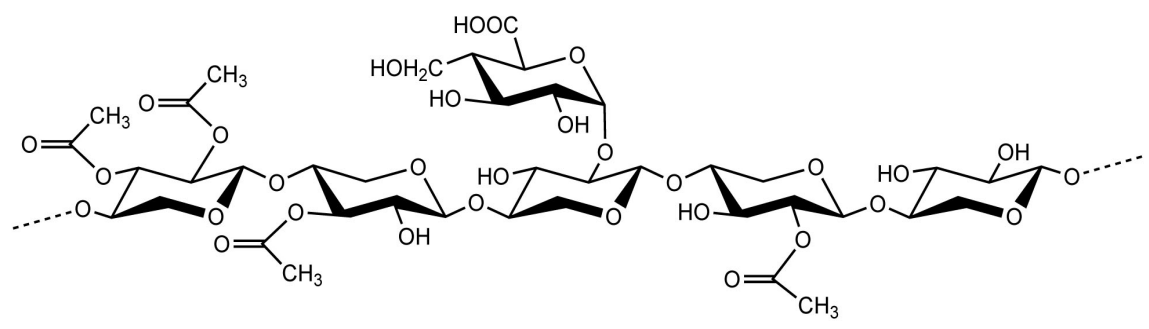

Figure 4. Structure of hemicellulose.

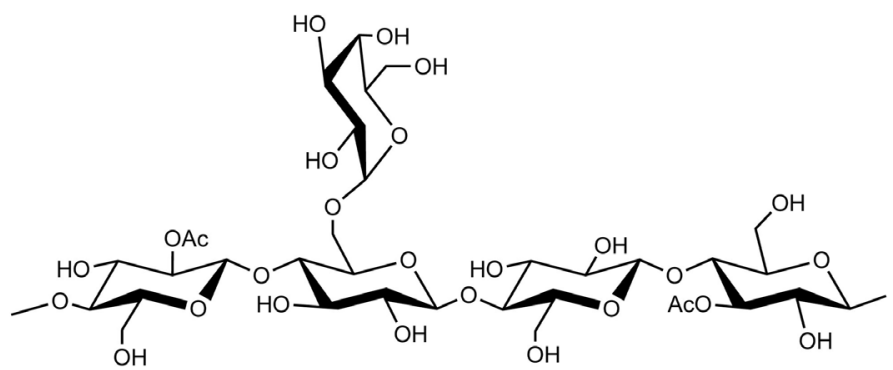

Figure 5. Chemical structure of softwoods: galactoglucomannan [11].

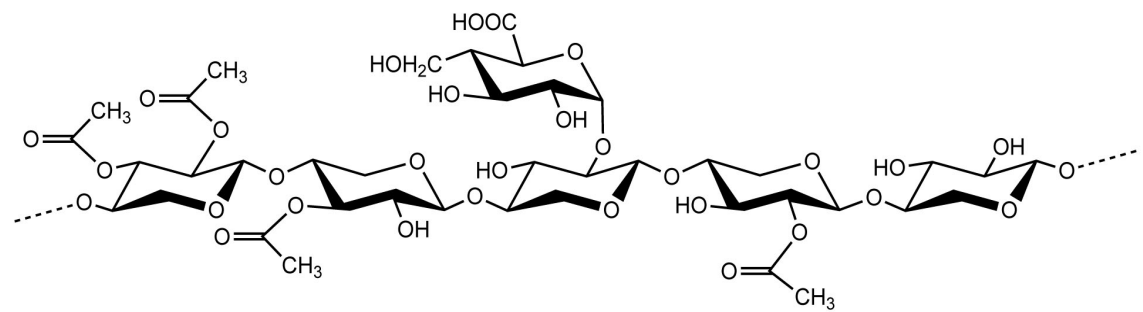

Figure 6. Chemical structure of hard woods: glucuronoxylan [11]. 


\subsection{Extraction and Purified Hemicellulose}

Several methods have been used to extract hemicellulose from woody tissues. Those methods include acid hydrolysis [14] [15], alkaline extraction [16], peroxide extraction [17], high temperature extraction [18], vapor treatment [19], microwave treatment [20], ionic liquid extraction [21], and other treatment [22]. Among these methods, acid hydrolysis, generally speaking, which often used $0.5 \%-1 \%$ sulfuric acid and hydrochloric acid is an effective method that could make the hemicellulose break down to low molecular weight product [23]. However, diluted acid method could cause environmental issues. On contrary, high temperature extraction at a temperature of $150^{\circ} \mathrm{C}$ to $170^{\circ} \mathrm{C}$ obtained high yield sugar and less degradation product. Due to acetate group in hemicellulose, when high temperature extractions begin, numbers of hydrogen ion in solution becomes high, which speed up hydrolysis reaction. And this process is called auto-hydrolysis [24]. Steam and microwave methods usually assisting other methods are usually to promote reactions and shorten reaction time. But, because of high requirement of equipment, these methods have been applied on a small-scale extraction. Froschauer et al. preparation of hemicellulose from wood pulp applied ionic liquid. In this study, hemicellulose was removed off by ionic liquid 1-ethyl-3methylimiazolium acetate, and high-level purity of pulp was obtained. Due to preparation of oligo- and long chain polymers rather than sugars, alkaline extraction was well studied in much biomass $r$ hydrolysis of hemicellulose. In a word, which method was adopted to prepare hemicellulose depends on what kind of final product is required. For example, if your objective product is bioethanol, sugars, furfural. You should adopt the diluted acid method [25].

\subsection{Chemical Reactions}

Due to its hydroxyl groups, which can serve as a reaction site, hemicellulose properties can modify by reactions with numerous chemical agents. After modification the polymers intensified their hydrophobicity and improve their water resistant, thermal stability and thermo plastics. The main reactions are follows: esterification, acetylation, etherification, oleoylation, crosslink, fluorination, benzylation [26] [27] [28] [29] [30].

Because of presence of large amount hydroxyl group, hemicellulose like alcohol could react with acids, acid anhydrides, acid chlorides [31]. These reactions can highly change the properties of hemicellulose, because of substitution of hydroxyl groups. In fact, modified hemicellulose has great water proof, thermoplastic and other properties. In research by Fang and coworkers, hemicellulose from wheat straw was reacted with acyl chlorides as illustrated in Figure 7 [32]; reaction time, reaction temperature, substance molar ratios and catalyst concentrations were investigated. And the results showed different reaction parameters would change the degree of substitution (DS) of hemicellulose. Pen et al. studied on esterification of hemicellulose isolated from Dendrocalamus membranaceus Munro by an alkaline extraction with maleic anhydride in ionic liquid. In this 


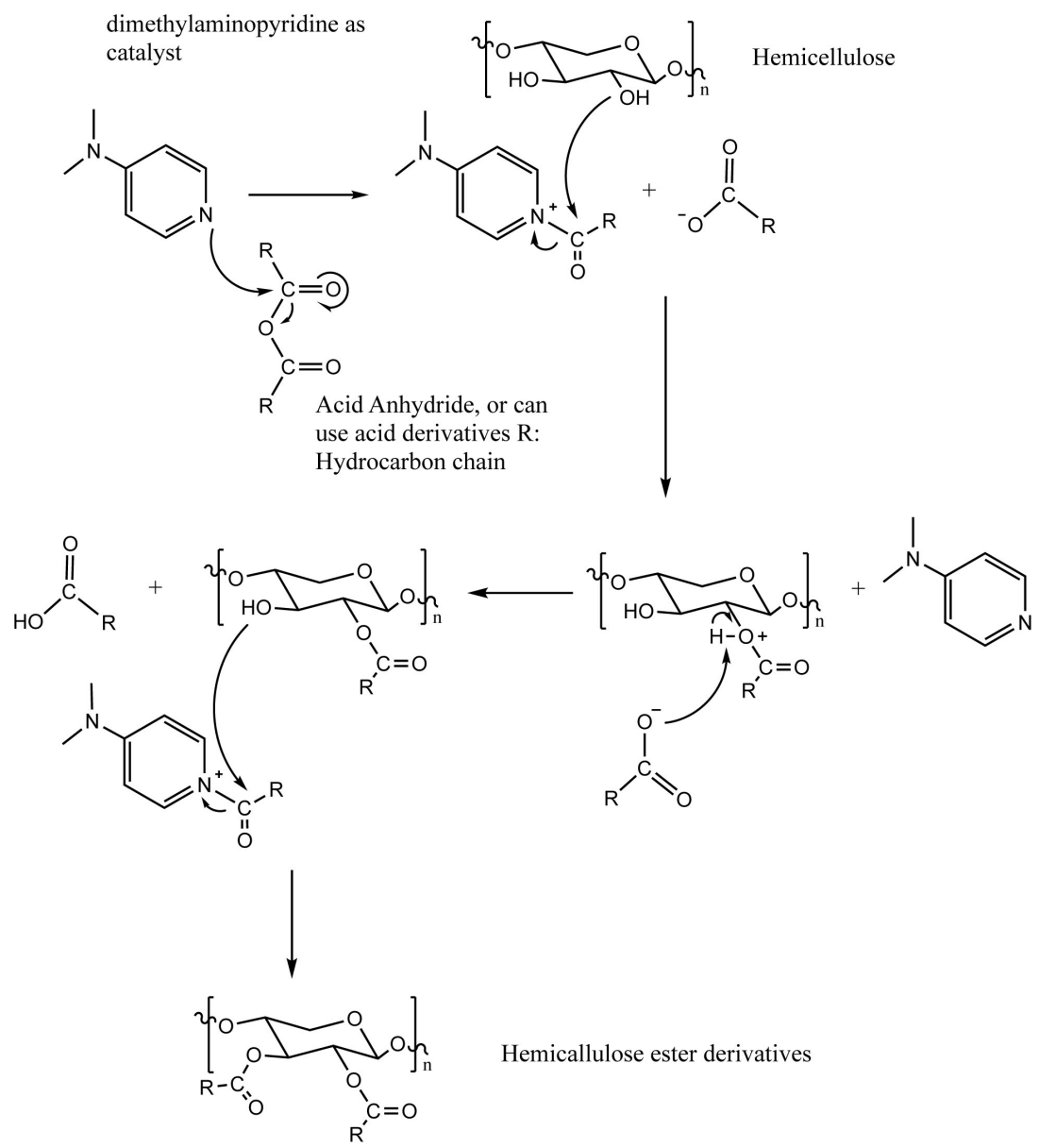

Figure 7. Mechanism of hemicellulose esterification with an acid anhydride and catalyst.

study, based on different reactions, the DS can vary at range from 0.095 to 0.75 [33]. hemicellulose acetylation a kind of esterification has been reported frequently [12] [34] [35]. Acetylation has been attained by several pathways. However, the most effective way is that hemicellulose reacts with acetic anhydride with catalysts [36].

Oleolation of hemicellulose is also an esterification. Generally, hemicellulose esterification is facile with fatty acid chloride, the reaction formula is illustrated in Figure 8. The oleolation of hemicellulose has shown the good water resistant properties, due to long chain of fatty acids that can be applied as coat on paper [37] [38] [39].

Fluorination of hemicellulose can provide modified hemicellulose with unique chemical property especially applied in marine as coatings [40]. The fluorination of hemicellulose was prepared by the reaction of arabinoxylan with gaseous trifluoroacetic anhydride (TFAA) to yield hydrophobic films with potential as food pack especially under alkaline conditions. Grondahl and coworkers synthesized the fluorination hemicellulose and verified the function group with FTIR spectroscopy and characterized the hydrophobic ability employed contact angle equipment with water drop on the surface [41]. 


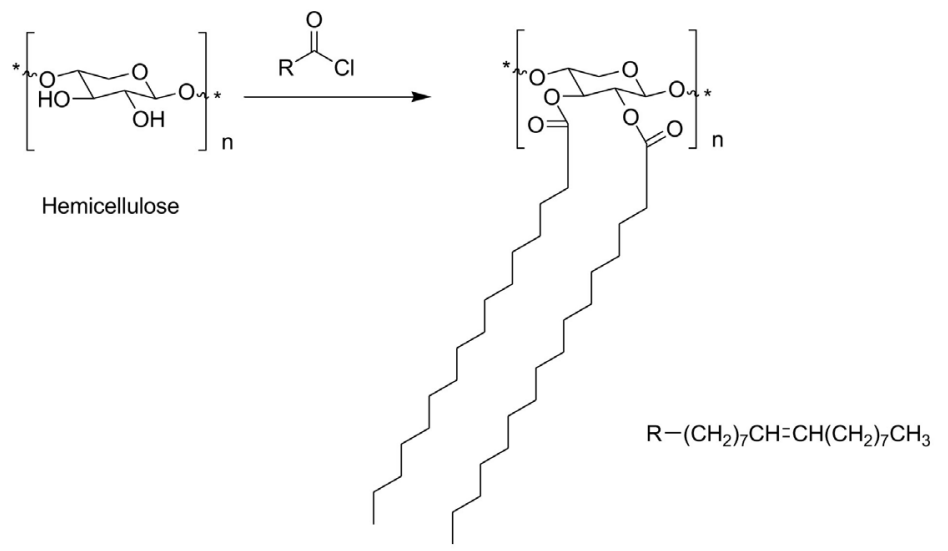

Figure 8. Oleolation of hemicellulos.

Hemicellulose cross-linking is mostly used to make hydrogels which have restricted water solubility and swell in water [42]. Salam and his coworkers firstly prepared esterification hemicellulose via reaction with citric acid, secondly cross linking with chitosan in an aqueous medium. The final product is elastic, soft, highly porous and durable and apt to be applied in health care and medical textiles [13]. In another study performed by Maleki et al. thiolation o-acetyl-galactoglucomannans (AcGGM) were created by the AcGGM-mediated mucleophilic ring-opening of thiobutyrolactone via the activation of the polysaccharide pendant hydroxy groups. The synthetic methodology of the reaction is merged with click chemistry [43].

Etherification is a reaction that usually alcohols (include some hydroxyl group chemicals) and alkylating agent as reactants under catalysts of base. Alkylating agents usually are alkyl halides such as chlorides, bromides and iodides and epoxides. Epoxides are apt to react with alcohols due to the epoxides have unstable three-membered ring. Because of ether bond is more stable than ester bond, the etherification hemicellulose is more stable and hydrophobic ability than esterification hemicellulose. Thus, a lot of research have been done to etherify hemicellulose with alkylating agents [32] [44] [45]. Hydroxylated xylan has been performed for coating applications. Laine et al. reported that etherified hemicellulose from birch pulp and native hemicellulose by alkaline extraction. In this research, the results showed that vapor permeabilities of the coatings were $50 \%$ $100 \%$ of that measured for polyethylene terephthalate coating as a commercial biopolymer coating. Furthermore, it was indicated that the oxygen permeability was one-third of that for a commercial biopolymer coating. In addition, it has been shown that the surface strength of butylated and alkylated xylan coating was close to that of the reference latex as a binder in pigment coatings [46].

\section{Applications}

Hemicellulose as prospect biomass resource attracts much attention, because it is sustainable, renewable and environment friendly. The Hemicellulose based materials e.g. biofilms [47] [48] [49] [50] such as food packing materials [51], hy- 
drogels also show high potential for utilization in remarkable applications, coatings [52] [53], wound dressing [54] [55] [56], drug delivery vessels [57] [58] and so on.

\subsection{Hydrogels}

Polymeric hydrogels have defined a remarkable research area, mainly due to their wide range of applications, such as matrix chemistry and biology, the removal of endocrine disruptors, media for the delivery of substances in biomedicine, and scaffolds. Hydrogels have potential in biomedical applications due to their good biocompatibility and ability to selectively mimic human tissues. Natural polymer-based hydrogels, such as those made from proteins and polysaccharides, are widely used in injectable engineering, controlled drug release, biosensors, and articular cartilage tissue engineering because they are commonly biocompatible, degradable, capable of promoting cell adhesion and proliferation, and immunologically inert. Hemicellulose-based hydrogels are currently being acknowledged for their non-toxic and renewable properties in addition to the advantages of natural polymers mentioned above [59]. Pen and his coworkers prepared novel ionic hydrogels via free radical graft copolymerization of acrylic acid and xylan-rich hemicelluloses using N,N-methylene-bis-(acrylamide) as cross-linker and ammonium salts as redox initiator. The results showed that the ionic hydrogels had high water adsorption capacity and rapid and multiple responses to $\mathrm{pH}$, ions, and organic solvents, which may allow their use in several areas such as adsorption, separation, and drug release systems [60]. Another study, full interpenetrating polymer networks (IPNs) was developed by performed with O-acetyl-galactoglucomannan via thiolene click reaction. The AcGGM IPNs fabricated had shear storage modulus $(G)$ values than that of the corresponding precursor single networks of AcGGM [43].

\subsection{Conductive Polymers}

Conducting polymers are the polymers which could conduct electricity, that has been widely applied to fabricate electrochemical biosensors, the reason is that this kind of polymers present of conjugated double bond or triple bond, in addition, conductive polymers have ability of conduct both electronically and ionically [61]. Other kinds of conducting materials are composites that blending some conducting materials particle to non-conducting polymer, so that the composites own conductivity. Conducting polymers and composites have attracted a lot of attention due to their wide application on soft materials, electrochemical biosensors, neural interface [62], drug delivery, bio erodible, tissues and other areas. In a research, electrically conductive hemicellulose hydrogels (ECHHs) is performed via cross-linking O-acetyl-galactoglucomannan (AcGGM) with epichlorohydrin in water at ambient temperature in the presence of conductive aniline pentamer (AP). The polymers have more pores and controllable conductivity, swelling behavior and middle strength mechanical properties, which could be applied in biomedical field [63]. In another of Zhao and 
his coworker's paper, they employ other synthetic ways to produce high strength hemicellulose based conductive hydrogels [64].

\subsection{Medical Application}

Biomedical applications of modified hemicellulose have attracted much attention on hydrophobization and/or cross-linking to produce water-resistant materials. Certain types of hemicelluloses have been used successfully to inhibit the growth of different tumors by inducing the activity of the host immune system

Hemicellulose based polymer with typical type could have the effect of antitumor and antimicrobial activities. The mechanism of antitumor is that galactan could stimulate NK cell cytotoxic activity, and thus, activate the immune system against tumor cells [65]. One research showed that mannose has bioactivity to conjugate to vaccine; this could be applied as a target for cancer immunotherapy [66].

Hemicellulose has also been used as a wound dressing. An ideal wound dressing should keep moisture and good ventilation to environment and release the wound pain. In market, there is similar product called Veloderm, which is a biofilm with a polymeric structure based on hemicellulose microfibers. It is produced from sugarcane by a biotechnological process. It has been distributed into the market as a competitor to other wound dressings. This company describes Veloderm as a wound dressing that is able to allow the selective permeability of gases and vapor and prevent the permeability of water and microorganisms. They describe its ability to adhere to the wound and generate a sealing process that protects the wound externally from dirt and germs [25].

\section{Outlook}

Hemicellulose as a second abundant resource on the earth has a large amount of hydroxyl group that leads to drawbacks of applications. Through reacting with hydroxyl group of hemicelluloses, properties of hemicellulose are changed from hydrophilic into hydrophobic. Modified chemical methods mainly include esterification, etherification, crosslinking etc. This reaction can be used to alter hemicellulose hydrophobicity and improve hemicellulose miscibility, thermoplastic stability and mechanical properties. In addition, hemicellulose cross-linking has been developed to create hydrogels used as drug-delivery systems or as water-absorption hydrogels. Recent research into hemicellulose-based conductive hydrogels has combined hemicellulose with chitosan to create a matrix capable of overcoming acidic conditions. Moreover, despite the fact that pharmaceutical applications of hemicelluloses are relatively new, we can anticipate that hemicelluloses can incorporate diverse biomolecules; thus, providing a promising structure for the preparation of new drug-delivery systems. A focus on green pathways that use green solvents and reactants for hemicellulose derivatization must be considered in future applications.

\section{Acknowledgements}

The authors gratefully acknowledge Xiujun Chai for providing us lab assistance. 
This work was supported by China Ministry of Science and Technology (2016 YFD0600803).

\section{Conflicts of Interest}

The authors declare no conflicts of interest regarding the publication of this paper.

\section{References}

[1] Finnerty, W.R. (1992) Fossil Resource Biotechnology: Challenges and Prospects. Current Opinion in Biotechnology, 3, 277-282. https://doi.org/10.1016/0958-1669(92)90104-Q

[2] Brower, K.R. (2006) Measuring the Efficiency of Biomass Energy. Science, 312, 1744-1745. https://doi.org/10.1126/science.312.5781.1744

[3] McCann, M.C. and Carpita, N.C. (2008) Designing the Deconstruction of Plant Cell Walls. Current Opinion in Plant Biology, 11, 314-320.

https://doi.org/10.1016/j.pbi.2008.04.001

[4] Sanders, J., Scott, E., Weusthuis, R. and Mooibroek, H. (2007) Bio-Refinery as the Bio-Inspired Process to Bulk Chemicals. Macromolecular Bioscience, 7, 105-117. https://doi.org/10.1002/mabi.200600223

[5] Sjöström, E. (1993) The Structure of Wood. In: Sjöström, E., Ed., Wood Chemistry, Elsevier, Amsterdam, 1-20. https://doi.org/10.1016/B978-0-08-092589-9.50005-X

[6] Jara, R. (2010) The Removal of Wood Components from Hardwood by Hot Water. PhD Thesis.

[7] Scheller, H.V. and Ulvskov, P. (2010) Hemicelluloses. Annual Review of Plant Biology, 61, 263-289. https://doi.org/10.1146/annurev-arplant-042809-112315

[8] Cunha, A.G. and Gandini, A. (2010) Turning Polysaccharides into Hydrophobic Materials: A Critical Review. Part 2. Hemicelluloses, Chitin/Chitosan, Starch, Pectin and Alginates. Cellulose, 17, 1045-1065. https://doi.org/10.1007/s10570-010-9435-5

[9] Ebringerová, A. (2005) Structural Diversity and Application Potential of Hemicelluloses. Macro-Molecular Symposia, 232, 1-12. https://doi.org/10.1002/masy.200551401

[10] Ebringerová, A. and Heinze, T. (2000) Xylan and Xylan Derivatives-Biopolymers with Valuable Properties, 1. Naturally Occurring Xylans Structures, Isolation Procedures and Properties. Macromolecular Rapid Communications, 21, 542-556. https://doi.org/10.1002/1521-3927(20000601)21:9<542::AID-MARC542>3.0.CO;2-7

[11] Hu, L.S., Du, M.H. and Zhang, J.P. (2018) Hemicellulose-Based Hydrogels Present Status and Application Prospects: A Brief Review. Open Journal of Forestry, 8, 15-28. https://doi.org/10.4236/ojf.2018.81002

[12] Ayoub, A., Venditti, R.A., Pawlak, J.J., Sadeghifar, H. and Salam, A. (2013) Development of an Acetylation Reaction of Switchgrass Hemicellulose in Ionic Liquid without Catalyst. Industrial Crops and Products, 44, 306-314. https://doi.org/10.1016/j.indcrop.2012.10.036

[13] Salam, A., Venditti, R.A., Pawlak, J.J. and El-Tahlawy, K. (2011) Crosslinked Hemicellulose Citrate-Chitosan Aerogel Foams. Carbohydrate Polymers, 84, 1221-1229. https://doi.org/10.1016/j.carbpol.2011.01.008

[14] Nguyen, Q.A., Tucker, M.P., Keller, F.A. and Eddy, F.P. (2000) Two-Stage Dilute-Acid Pretreatment of Softwoods. Applied Biochemistry and Biotechnology, 
84-86, 561-576. https://doi.org/10.1385/ABAB:84-86:1-9:561

[15] Grous, W.R., Converse, A.O. and Grethlein, H.E. (1986) Effect of Steam Explosion Pretreatment on Pore Size and Enzymatic Hydrolysis of Poplar. Enzyme and Microbial Technology, 8, 274-280. https://doi.org/10.1016/0141-0229(86)90021-9

[16] Egüés, I., Sanchez, C., Mondragon, I. and Labidi, J. (2012) Effect of Alkaline and Autohydrolysis Processes on the Purity of Obtained Hemicelluloses from Corn Stalks. Bioresource Technology, 103, 239-248. https://doi.org/10.1016/j.biortech.2011.09.139

[17] Doner, L.W. and Hicks, K.B. (1997) Isolation of Hemicellulose from Corn Fiber by Alkaline Hydrogen Peroxide Extraction. Cereal Chemistry, 74, 176-181. https://doi.org/10.1094/CCHEM.1997.74.2.176

[18] Hasegawa, I., Tabata, K., Okuma, O. and Mae, K. (2004) New Pretreatment Methods Combining a Hot Water Treatment and Water/Acetone Extraction for Thermochemical Conversion of Biomass. Energy \& Fuels, 18, 755-760. https://doi.org/10.1021/ef030148e

[19] Palm, M. and Zacchi, G. (2003) Extraction of Hemicellulosic Oligosaccharides from Spruce Using Microwave Oven or Steam Treatment. Biomacromolecules, 4, 617-623. https://doi.org/10.1021/bm020112d

[20] Azhar, S., Henriksson, G., Theliander, H. and Lindström, M.E. (2015) Extraction of Hemicelluloses from Fiberized Spruce Wood. Carbohydrate Polymers, 117, 19-24. https://doi.org/10.1016/j.carbpol.2014.09.050

[21] Froschauer, C., Hummel, M., Iakovlev, M., Roselli, A., Schottenberger, H. and Sixta, H. (2013) Separation of Hemicellulose and Cellulose from Wood Pulp by Means of Ionic Liquid/Cosolvent Systems. Biomacromolecules, 14, 1741-1750. https://doi.org/10.1021/bm400106h

[22] Dibble, D.C., Li, C.L., Sun, L., George, A., Cheng, A., Çetinkol, Ö.P., Benke, P., Holmes, B.M., Singh, S. and Simmons, B.A. (2011) A Facile Method for the Recovery of Ionic Liquid and Lignin from Biomass Pretreatment. Green Chemistry, 13, 3255-3264. https://doi.org/10.1039/c1gc15111h

[23] Lee, J.M., Shi, J., Venditti, R.A. and Jameel, H. (2009) Autohydrolysis Pretreatment of Coastal Bermuda Grass for Increased Enzyme Hydrolysis. Bioresource Technology, 100, 6434-6441. https://doi.org/10.1016/j.biortech.2008.12.068

[24] Knappert, D., Grethlein, H. and Converse, A. (1980) Partial Acid Hydrolysis of Cellulosic Materials as a Pretreatment for Enzymatic Hydrolysis. Biotechnology and Bioengineering, 22, 1449-1463. https://doi.org/10.1002/bit.260220711

[25] Farhat, W., Venditti, R.A., Hubbe, M., Taha, M., Becquart, F. and Ayoub, A. (2017) A Review of Water-Resistant Hemicellulose-Based Materials: Processing and Applications. ChemSusChem, 10, 305-323. https://doi.org/10.1002/cssc.201601047

[26] Peng, X.-W., Ren, J.-L., Zhong, L.-X. and Sun, R.-C. (2012) Synthesis and Characterization of Amphoteric Xylan-Type Hemicelluloses by Microwave Irradiation. Journal of Agricultural and Food Chemistry, 60, 1695-1702. https://doi.org/10.1021/jf204522k

[27] Vega, B., Petzold-Welcke, K., Fardim, P. and Heinze, T. (2012) Studies on the Fibre Surfaces Modified with Xylan Polyelectrolytes. Carbohydrate Polymers, 89, 768-776. https://doi.org/10.1016/j.carbpol.2012.04.006

[28] Bigand, V., Pinel, C., Da Silva Perez, D., Rataboul, F., Huber, P. and Conil, M.P. (2011) Cationisation of Galactomannan and Xylan Hemicelluloses. Carbohydrate Polymers, 85, 138-148. https://doi.org/10.1016/j.carbpol.2011.02.005 
[29] Heinze, T., Petzold, K. and Schubert, S. (2008) Novel Nanoparticles Based on Xylan. Cellulose Chemistry and Technology, 41, 13-18.

[30] Petzold, K., Schwikal, K. and Heinze, T. (2006) Carboxymethyl Xylan-Synthesis and Detailed Structure Characterization. Carbohydrate Polymers, 64, 292-298. https://doi.org/10.1016/j.carbpol.2005.11.037

[31] Šimkovic, I. and Alföldi, J. (1990) Acetylation of (4-o-methyl-d-glucurono)-d-xylan under Homogeneous Conditions Using Trifluoroacetic Acid-Acetic Anhydride. Carbohydrate Research, 201, 346-348. https://doi.org/10.1016/0008-6215(90)84251-O

[32] Fang, J. (2002) The Preparation and Characterisation of a Series of Chemically Modified Potato Starches. Carbohydrate Polymers, 47, 245-252. https://doi.org/10.1016/S0144-8617(01)00187-4

[33] Peng, X.-W., Ren, J.-L. and Sun, R.-C. (2010) Homogeneous Esterification of Xylan-Rich Hemicelluloses with Maleic Anhydride in Ionic Liquid. Biomacromolecules, 11, 3519-3524. https://doi.org/10.1021/bm1010118

[34] Fundador, N.G.V., Enomoto-Rogers, Y., Takemura, A. and Iwata, T. (2012) Acetylation and Characterization of Xylan from Hardwood Kraft Pulp. Carbohydrate Polymers, 87, 170-176. https://doi.org/10.1016/j.carbpol.2011.07.034

[35] Ren, J.L., Sun, R.C., Liu, C.F., Cao, Z.N. and Luo, W. (2007) Acetylation of Wheat Straw Hemicelluloses in Ionic Liquid Using Iodine as a Catalyst. Carbohydrate Polymers, 70, 406-414. https://doi.org/10.1016/j.carbpol.2007.04.022

[36] Sun, R.C., Tomkinson, J., Ma, P.L. and Liang, S.F. (2000) Comparative Study of Hemicelluloses from Rice Straw by Alkali and Hydrogen Peroxide Treatments. Carbohydrate Polymers, 42, 111-122. https://doi.org/10.1016/S0144-8617(99)00136-8

[37] Freire, C.S.R., Silvestre, A.J.D., Pascoal Neto, C., Belgacem, M.N. and Gandini, A. (2006) Controlled Heterogeneous Modification of Cellulose Fibers with Fatty Acids: Effect of Reaction Conditions on the Extent of Esterification and Fiber Properties. Journal of Applied Polymer Science, 100, 1093-1102. https://doi.org/10.1002/app.23454

[38] Sebti, I., Ham-Pichavant, F. and Coma, V. (2002) Edible Bioactive Fatty Acid-Cellulosic Derivative Composites Used in Food-Packaging Applications. Journal of Agricultural and Food Chemistry, 50, 4290-4294. https://doi.org/10.1021/jf0115488

[39] Sun, X.-F., Sun, R.-C. and Sun, J.-X. (2004) Oleoylation of Sugarcane Bagasse Hemicelluloses Using n-Bromosuccinimide as a Catalyst. Journal of the Science of Food and Agriculture, 84, 800-810. https://doi.org/10.1002/jsfa.1735

[40] Tressaud, A., Durand, E., Labrugère, C., Kharitonov, A.P. and Kharitonova, L.N. (2007) Modification of Surface Properties of Carbon-Based and Polymeric Materials through Fluorination Routes: From Fundamental Research to Industrial Applications. Journal of Fluorine Chemistry, 128, 378-391.

https://doi.org/10.1016/j.jfluchem.2006.12.015

[41] Gröndahl, M., Gustafsson, A. and Gatenholm, P. (2006) Gas-Phase Surface Fluorination of Arabinoxylan Films. Macromolecules, 39, 2718-2721.

https://doi.org/10.1021/ma052066q

[42] Peng, X.-W., Ren, J.-L., Zhong, L.-X., Peng, F. and Sun, R.-C. (2011) Xylan-Rich Hemicelluloses-Graft-Acrylic Acid Ionic Hydrogels with Rapid Responses to $\mathrm{pH}$, Salt, and Organic Solvents. Journal of Agricultural and Food Chemistry, 59, 8208-8215. https://doi.org/10.1021/jf201589y 
[43] Maleki, L., Edlund, U. and Albertsson, A.-C. (2015) Thiolated Hemicellulose as a Versatile Platform for One-Pot Click-Type Hydrogel Synthesis. Biomacromolecules, 16, 667-674. https://doi.org/10.1021/bm5018468

[44] Ren, J.L., Peng, X.W., Zhong, L.X., Peng, F. and Sun, R.C. (2012) Novel Hydrophobic Hemicelluloses: Synthesis and Characteristic. Carbohydrate Polymers, 89, 152-157. https://doi.org/10.1016/j.carbpol.2012.02.064

[45] Pourchez, J., Govin, A., Grosseau, P., Guyonnet, R., Guilhot, B. and Ruot, B. (2006) Alkaline Stability of Cellulose Ethers and Impact of Their Degradation Products on Cement Hydration. Cement and Concrete Research, 36, 1252-1256.

https://doi.org/10.1016/j.cemconres.2006.03.028

[46] Laine, C., Harlin, A., Hartman, J., Hyvärinen, S., Kammiovirta, K., Krogerus, B., Pajari, H., Rautkoski, H., Setälä, H., Sievänen, J., Uotila, J. and Vähä-Nissi, M. (2013) Hydroxyalkylated Xylans-Their Synthesis and Application in Coatings for Packaging and Paper. Industrial Crops and Products, 44, 692-704. https://doi.org/10.1016/j.indcrop.2012.08.033

[47] Edlund, U., Ryberg, Y.Z. and Albertsson, A.-C. (2010) Barrier Films from Renewable Forestry Waste. Biomacromolecules, 11, 2532-2538. https://doi.org/10.1021/bm100767g

[48] Mikkonen, K.S., Heikkilä, M.I., Helén, H., Hyvönen, L. and Tenkanen, M. (2010) Spruce Galactoglucomannan Films Show Promising Barrier Properties. Carbohydrate Polymers, 79, 1107-1112. https://doi.org/10.1016/j.carbpol.2009.10.049

[49] Alekhina, M., Mikkonen, K.S., Alén, R., Tenkanen, M. and Sixta, H. (2014) Carboxymethylation of Alkali Extracted Xylan for Preparation of Bio-Based Packaging Films. Carbohydrate Polymers, 100, 89-96. https://doi.org/10.1016/j.carbpol.2013.03.048

[50] Methacanon, P., Chaikumpollert, O., Thavorniti, P. and Suchiva, K. (2003) Hemicellulosic Polymer from Vetiver Grass and Its Physicochemical Properties. Carbohydrate Polymers, 54, 335-342. https://doi.org/10.1016/S0144-8617(03)00182-6

[51] Mikkonen, K.S. and Tenkanen, M. (2012) Sustainable Food-Packaging Materials Based on Future Biorefinery Products: Xylans and Mannans. Trends in Food Science Technology, 28, 90-102. https://doi.org/10.1016/j.tifs.2012.06.012

[52] Hansen, N.M.L. and Plackett, D. (2008) Sustainable Films and Coatings from Hemicelluloses: A Review. Biomacromolecules, 9, 1493-1505. https://doi.org/10.1021/bm800053z

[53] Tatar, F., Tunç, M.T., Dervisoglu, M., Cekmecelioglu, D. and Kahyaoglu, T. (2014) Evaluation of Hemicellulose as a Coating Material with Gum Arabic for Food Microencapsulation. Food Research International, 57, 168-175. https://doi.org/10.1016/j.foodres.2014.01.022

[54] Kennedy, J.F., Methacanon, P., Lloyd, L.L., Paterson, M. and Knill, C.J. (1997) Carbohydrate Polymers as Wound Management Aids. Carbohydrate Polymers, 34, 422. https://doi.org/10.1016/S0144-8617(97)87338-9

[55] Miraftab, M., Qiao, Q., Kennedy, J.F., Anand, S.C. and Groocock, M.R. (2003) Fibres for Wound Dressings Based on Mixed Carbohydrate Polymer Fibres. Carbohydrate Polymers, 53, 225-231. https://doi.org/10.1016/S0144-8617(03)00108-5

[56] Melandri, D., De Angelis, A., Orioli, R., Ponzielli, G., Lualdi, P., Giarratana, N. and Reiner, V. (2006) Use of a New Hemicellulose Dressing (veloderm ${ }^{\circledR}$ ) for the Treatment of Split-Thickness Skin Graft Donor Sites: A Within-Patient Controlled Study. Burns, 32, 964-972. https://doi.org/10.1016/j.burns.2006.03.013

[57] Sun, X.-F., Wang, H.H., Jing, Z.X. and Mohanathas, R. (2013) Hemicellulose-Based 
Ph-Sensitive and Biodegradable Hydrogel for Controlled Drug Delivery. Carbohydrate Polymers, 92, 1357-1366. https://doi.org/10.1016/j.carbpol.2012.10.032

[58] Zhao, W.F., Odelius, K., Edlund, U., Zhao, C.S. and Albertsson, A.-C. (2015) In Situ Synthesis of Magnetic Field-Responsive Hemicellulose Hydrogels for Drug Delivery. Biomacromolecules, 16, 2522-2528. https://doi.org/10.1021/acs.biomac.5b00801

[59] Maleki, L., Edlund, U. and Albertsson, A.-C. (2014) Unrefined Wood Hydrolysates Are Viable Reactants for the Reproducible Synthesis of Highly Swellable Hydrogels. Carbohydrate Polymers, 108, 281-290. https://doi.org/10.1016/j.carbpol.2014.02.060

[60] Zhong, L.-X., Peng, X.-W., Yang, D., Cao, X.-F. and Sun, R.-C. (2013) Long-Chain Anhydride Modification: A New Strategy for Preparing Xylan Films. Journal of Agricultural and Food Chemistry, 61, 655-661. https://doi.org/10.1021/jf304818f

[61] Owens, R.M. and Malliaras, G.G. (2010) Organic Electronics at the Interface with Biology. MRS Bulletin, 35, 449-456. https://doi.org/10.1557/mrs2010.583

[62] Detsch, R., Will, J., Hum, J., Roether, J.A. and Boccaccini, A.R. (2018) Biomaterials. In: Cell Culture Technology, Springer International Publishing, Berlin, 91-105. https://doi.org/10.1007/978-3-319-74854-2_6

[63] Zhao, W.F., Glavas, L., Odelius, K., Edlund, U. and Albertsson, A.-C. (2014) Facile and Green Approach towards Electrically Conductive Hemicellulose Hydrogels with Tunable Conductivity and Swelling Behavior. Chemistry of Materials, 26, 4265-4273. https://doi.org/10.1021/cm501852w

[64] Zhao, W.F., Glavas, L., Odelius, K., Edlund, U. and Albertsson, A.-C. (2014) A Robust Pathway to Electrically Conductive Hemicellulose Hydrogels with High and Controllable Swelling Behavior. Polymer, 55, 2967-2976. https://doi.org/10.1016/j.polymer.2014.05.003

[65] Kelly, G.S. (1999) Larch Arabinogalactan: Clinical Relevance of a Novel Immune-Enhancing Polysaccharide. Alternative Medicine Review: A Journal of Clinical Therapeutic, 4, 96-103.

[66] Apostolopoulos, V., Pietersz, G.A., Tsibanis, A., Tsikkinis, A., Drakaki, H., Loveland, B.E., Piddlesden, S.J., Plebanski, M., Pouniotis, D.S., Alexis, M.N., et al. (2006) Pilot Phase III Immunotherapy Study in Early-Stage Breast Cancer Patients Using Oxidized Mannan-muc1 [isrctn71711835]. Breast Cancer Research, 8, R27. https://doi.org/10.1186/bcr1505 